\title{
Electrodeposition of Antimony from Hydrated Ammonium Aluminum Sulfate-Urea Room Temperature Ionic Liquid
}

\author{
Hadi M. A. Abood and Azal U. Ahmed \\ Department of Chemistry, College of Science, University of Al-Nahrain, Baghdad-Iraq. \\ Corresponding Author: College of Science.
}

\begin{abstract}
The electrochemical stability of antimony in a water stable room temperature ionic liquid composed of 1:5 mole ratio of hydrated ammonium aluminum sulfate - urea ionic liquid at $30{ }^{\circ} \mathrm{C}$ was investigated at $0.3 \mathrm{M}$ antimony (III) chloride solution. The electroplating of antimony at $-0.8 \mathrm{~V}$ showed black coating on copper substrate. The stability of this cation in this ionic liquid was studied by cyclovoltammogram. The electrodeposition was followed up by Scanning Electron Microscopy (SEM), Atomic Force Microscopy (AFM), Energy Dispersive X-ray analysis (EDAX) and X-ray diffraction (XRD). The nanoparticles size of the metal were in the range of less than 500nm. [DOI: $10.22401 /$ JNUS.20.4.02]

Keywords: electroplating, nano particles antimony, ammonium alum/urea ionic liquid, cyclovoltammetry.
\end{abstract}

\section{Introduction}

Room temperature ionic liquids [1-4] have attracted intensive interest in recent years as a replacement for classical molecular solvents in fundamental research and applications, included electrodeposition, batteries, catalysis, separations and organic synthesis. The advantages of these ionic liquids include good thermal stability, low vapor pressure, high conductivity, wide electrochemical window and good solvents for both organic and inorganic compounds. The first group of ionic liquid systems that attracts attention is the chloroaluminates that are formed from dialkylimidazolium halides and aluminum halides. Although the chloroaluminate ionic liquids have found many applications in electrodeposition [5], a major disadvantage of the chloroaluminate systems is that they are extremely reactive towards moisture and air so they must be handled under an inert atmosphere. Since 1992[6], various air-and moisture-stable ionic liquids have become available. The appearance of these waterstable ionic liquids has greatly accelerated research and applications using ionic liquids.

The recently prepared $\mathrm{AlCl}_{3}$-Acetamide [7] ionic liquid by coordinating the metal chloride cations with the organic salts forming inorganic cations $\left[\mathrm{AlCl}_{2} \cdot \mathrm{n} \text { Amide }\right]^{+}$open a new era for preparing a more stable ionic liquids towards air with less handling requirements than the chloroaluminate ionic liquid. These ionic liquids were reported to be formed by $\mathrm{AlNH}_{4}\left(\mathrm{SO}_{4}\right)_{2} .12 \mathrm{H}_{2} \mathrm{O}$ :urea [8] and $\mathrm{Al}\left(\mathrm{NO}_{3}\right)_{3} \cdot 9 \mathrm{H}_{2} \mathrm{O}$ :urea [9].

These are interested ionic liquids because this type showed the characterization of ionic liquids and also containing water molecules which was reported to exists in the liquid coordinated to the ionic species of ionic liquid and not in the free state [10].

This is an interesting characterization as added water to anhydrous ionic liquid of $\mathrm{NiCl}_{2}$ :urea showed to influence the nature of deposited nickel[11].

Antimony which is a semimetallic element and a poor conductor of heat and electricity, was considered for many components because of its high corrosion resistance and nonoxidizing properties. While more critical metals are used such as hardware, infrared detectors and diodes, domestic ware, automotive trim and radio and radar equipment and to cover brass and lead alloys which require a high degree of corrosion protection [12]. Studies on the electrochemistry of antimony in ionic liquids are mainly reported by Osteryoung and coworkers [13]. Their results showed that $\mathrm{Sb}(\mathrm{III})$ can be reduced to $\mathrm{Sb}$ in ionic liquids made from aluminum chloride and N-butylpyridinium chloride 
$\left(\mathrm{AlCl}_{3}-\mathrm{BPC}\right)$. In view of the advantages of the room temperature ionic liquids over the chloroaluminates and the fact that there have been few studies on electrodeposition of antimony in room temperature ionic liquids, we report here the electrochemistry of antimony(III) and its electrodeposition in the recently reported ionic liquid prepared by Abood[8] in (1:5) mole ratio of the hydrated ammonium alum /urea. As stated this ionic liquid posses the characterization of ionic liquid having water molecules within its structure without the need to add extra water. The morphology of deposited antimony was elucidated with the aid of Scanning Electron Microscopy (SEM), Atomic Force Microscopy (AFM), Energy Dispersive X-ray Analysis (EDAX) and X-Ray Diffraction (XRD).

\section{Experimental Work}

Anhydrous Antimony Chloride $\left(\mathrm{SbCl}_{3}\right)$ and Hydrated Ammonium Aluminum Sulfate $\left[\mathrm{NH}_{4} \mathrm{Al}\left(\mathrm{SO}_{4}\right)_{2} .12 \mathrm{H}_{2} \mathrm{O}\right],(99 \%$ obtained from $\mathrm{BDH})$ and Urea $\left(\mathrm{NH}_{2} \mathrm{CONH}_{2}\right)(99.5 \%$ were obtained from THOMAS BAKER). Ammonium alum and urea in mole ratio of (1:5) were milled separately, mixed and heated gradually to $85^{\circ} \mathrm{C}$ with stirring until melted together producing colorless liquid [10]. The resulted melt was gradually cooled to room temperature and remained liquid and stored in sealed container. A proper amount $(0.684 \mathrm{~g})$ to make $0.3 \mathrm{M} \mathrm{SbCl}_{3}$ solution in ionic liquid was weighted out and added to the ionic liquid, stirred for 60 minutes at $85^{\circ} \mathrm{C}$ when a saturated white solution was obtained. Copper metal sheet of $60 \mathrm{~mm}^{*} 10 \mathrm{~mm} * 1 \mathrm{~mm}$ was used as cathode and immersed in the ionic liquid to $20 \mathrm{~mm}$ depth. The anode was a stainless steel plate of $50 \mathrm{~mm}^{*} 10 \mathrm{~mm} * 1 \mathrm{~mm}$ dimentions. Both electrodes pretreated by rubbing with sand paper followed by washing with deionized water, then immersed into $0.5 \% \mathrm{HCl}$, rinsed with deionized water and plunged in $0.5 \%$ $\mathrm{NaOH}$, finally both electrodes were rinsed with deionized water and acetone sequentially. A three-electrode system comprising a platinum electrode $(2 \mathrm{~mm})$ as the working electrode (WE), a platinum plate $\left(1 \mathrm{~cm}^{*} 1 \mathrm{~cm}^{*} 0.5 \mathrm{~cm}\right)$ as the counter electrode (CE) and a silver wire as the quasi reference electrode (RE) were used in the cyclic voltammogram. The platinum working electrode surface was freshly cleaned with water, polished with alumina before each scan and rinsed with distilled water at each polishing step. The instrument for cyclic voltammogram (CV) was recorded using Digilvy- Dy2300 Bipotentiostat. A constant voltage of $-0.8 \mathrm{~V}$ was applied using a power supply (Thurlby 15V-4A, England power supply) to control the current and the potential of electrodeposition process which was connected to the electrode of copper as cathode and stainless steel as anode in ionic liquid. The electroplated specimen at the end of each experiment was removed from the ionic liquid and immediately dipped in deionized water with stirring to remove ionic liquid and then rinsed with acetone and finally dried and stored for further analysis. The surface morphology of coated specimens by antimony on copper substrate was investigated with a high-resolution field emission scanning electron microscopy(SEM) (INSPECT S50), the surface topography of samples were analyzed by atomic force microscopy (AFM) (AA2000, Angstrom Advanced Inc.) contact mode. The X Flash 6110 Bruker EADX was used in conjunction with SEM. This was used for determination of the surface and composition of samples surface and the OLYMPUS BX 51-P POLARIZING MICROSCOPE was used for visual observation. The crystalline and phase identification of samples were determined using X-ray Diffractometer (PAN analytical Philips, X Pert PRO MPD PW 3040).

\section{Results and Discussion}

The cyclovoltammogram of saturated solution of $(0.3 \mathrm{M}) \mathrm{SbCl}_{3}$ in ionic liquid with scan rate of $50 \mathrm{mV}$ is shown in Fig.(1). When the potential was scanned negatively from the rest potential, a rise in current was recorded with increasing the negative potential started at $-0.5 \mathrm{~V} \quad\left(\mathrm{c}_{1}\right)$ the potential showed another increase at $-0.8 \mathrm{~V}\left(\mathrm{c}_{2}\right)$. The first cathodic potential $\left(c_{1}\right)$ is similar to that of ionic liquid cathodic reduction Fig.(1). The current of the second cathodic reduction $\left(\mathrm{c}_{2}\right)$ increased with increasing the negative scanning potential, yet it did not show a distinguished metal reduction wave probably overlapping with the reduction of the positive ionic liquid species. However, 
when the scan was reversed to the positive potential, no curve was recorded for an oxidation. This might indicate an irreversible process of the reduction of $\mathrm{Sb}^{3+} / \mathrm{Sb}$ that occurred on the working electrode. Fig.(1)

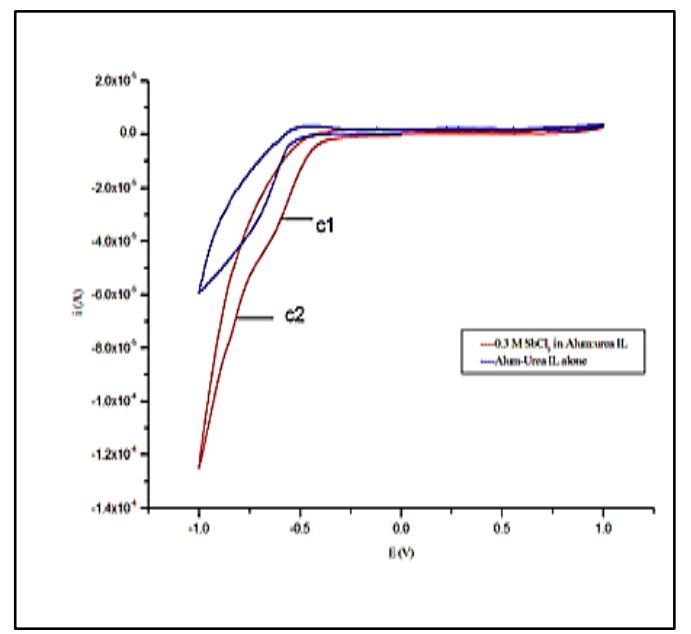

Fig.(1): Cyclovoltammogram of saturated solution (0.3M) $\mathrm{SbCl}_{3}$ in (1:5) ammonium alum: urea room temperature ionic liquid (------) and ionic liquid alone(-----) at 50 $m V$ scan rate using $A g$ wire $(R E), P t$ disc (WE) and Pt plate $(\mathrm{CE})$ at $30^{\circ} \mathrm{C}$.

The potentiostatic electroreduction of antimony from the saturated solution of $0.3 \mathrm{M} \mathrm{SbCl} \mathrm{Sb}_{3}$ in ammonium alum:urea room temperature ionic liquid at $30^{\circ} \mathrm{C}$ was conducted at $-0.8 \mathrm{~V}$ as estimated from the cyclovoltammogram. The experiments were carried out to show the effect of deposition time on the electroreduction of $\mathrm{Sb}^{3+}$ to $\mathrm{Sb}^{0}$. Therefore, the surface morphology of antimony electrodeposits was examined by SEM and the resulting micrographs are illustrated in Fig.(2). The SEM of the deposit surface showed the morphology of the deposited antimony as a plate shaped particle with some particles having nodules shape at one and two hours, while at three hours the particles were of sand-like shape. The particles size was found to range from $154 \mathrm{~nm}$ to $462 \mathrm{~nm}$, from $227 \mathrm{~nm}$ to $455 \mathrm{~nm}$ and from $217 \mathrm{~nm}$ to $435 \mathrm{~nm}$ at one, two and three hours samples respectively, as shown in Table (1). This indicated no effect of the deposition time on the morphology of deposited antimony giving almost similar range of nanoparticle size. The visual appearance of coated antimony was black as shown in Fig.(2)(b),(d) and (f), which might be related to the particle shapes, which disperse light allowing very small light reflection.

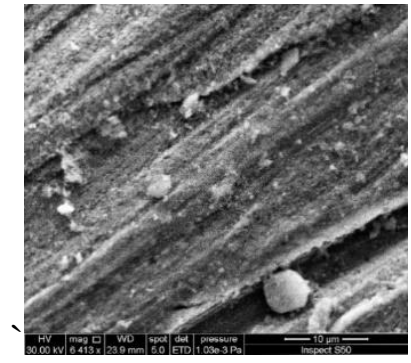

(a)

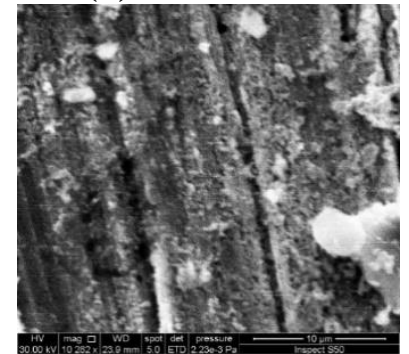

(c)

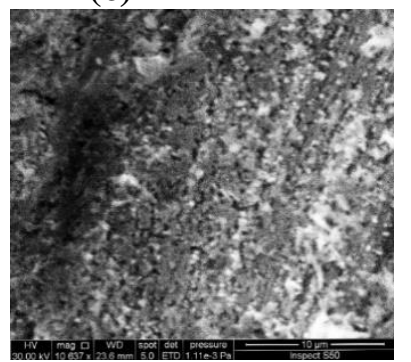

(e)

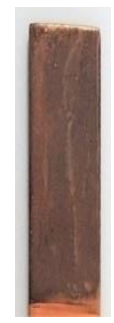

(b)

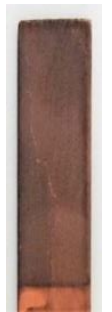

(d)

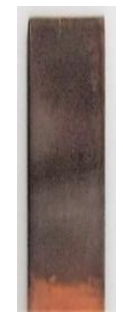

(f)
Fig.(2): SEM images of deposited antimony nanoparticles on copper substrate from 1:5 mole ratio ammonium alum: urea room temperature ionic liquid at $-0.7 \mathrm{~V}$ and $30^{\circ} \mathrm{C}$ after different deposition time (a)1h.,(c) $2 \mathrm{~h}$. and (e) 3h., the corresponding optical photograph of deposited antimony nanoparticles on copper substrate showed at (b)1h., (d) 2 h. and (f) 3 h.

The EDAX spectrum of antimony nanoparticles deposited on copper substrate appeared as $\mathrm{M}_{\alpha}$ and $\mathrm{L}_{\alpha}$ at (0.4 and 3.6) $\mathrm{Kev}$ as compared with standard values from energy table for EDAX analysis and as reported by H.Chauhan and coworkers [14], shown in Figure (3).The EDAX analysis confirmed the presence of small amounts of antimony with 3.47 At.\%, 3.95At.\% and 4.47At.\% at one, two and three hours samples respectively. Table(1). This indicated probably a limited soluble amount of $\mathrm{SbCl}_{3}$ in the ammonium alum: urea ionic liquid and imply a very slow rate of $\mathrm{SbCl}_{3}$ dissolution in ionic liquid since 
almost similar percentage of antimony was deposited at the two or the three hours of depositions (compare 3.47 At.\% at one hour with 3.95 At. $\%$ and 4.47 At.\% at two and three hours respectively).

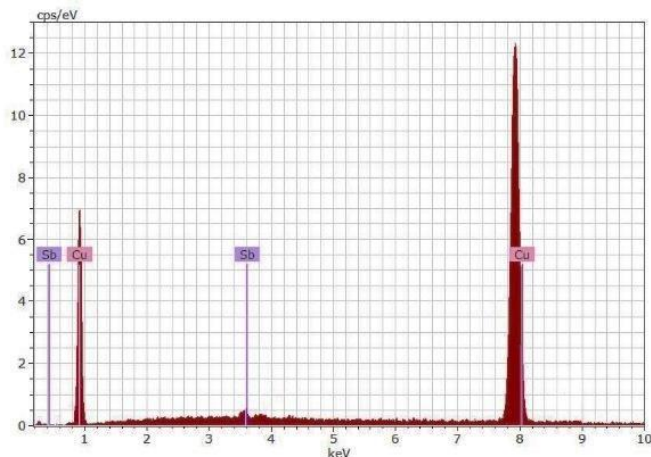

(a)

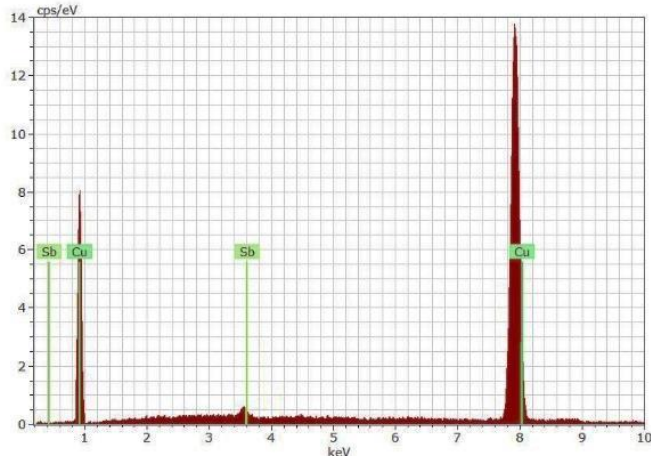

(b)

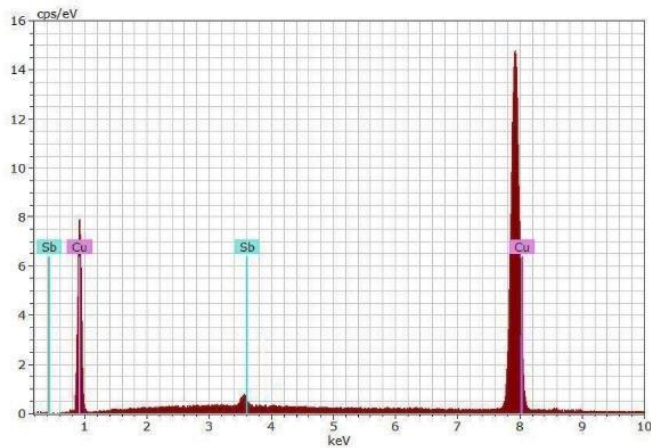

(c)

Fig.(3): EDAX spectra of deposited antimony nanoparticles on copper substrate from 1:5 mole ratio ammonium alum:urea room temperature ionic liquid at $-0.8 \mathrm{~V}$ and $30^{\circ} \mathrm{C}$ after different deposition time, (a)1h., (b)2h. and (c)3h.

AFM images of the electrodeposited antimony are shown in Fig.(4). The roughness value (Ra) was $(19.0 \mathrm{~nm})$ at one hour, decreased to $(15.9 \mathrm{~nm})$ at two hours, while at three hours the roughness value increased to $(26.9 \mathrm{~nm})$. Although the roughness are varied, these values indicated very smooth surfaces comparable to superfinishing metal process and within the range of Fly cut or Ground aluminum [15] which have $\mathrm{Ra}$ values of around $100 \mathrm{~nm}$ and very much better than milled aluminum which has $\mathrm{Ra}$ value around $1000 \mathrm{~nm}$. The average height of those deposited antimony have values of $(154.53 \mathrm{~nm})$ at one hour decreased to $(120.18 \mathrm{~nm})$ at two hours then increased to $(159.33 \mathrm{~nm})$ at three hours. These values indicated that the electrocoated antimony on copper substrate varies with time as agreed to the result obtained from SEM.

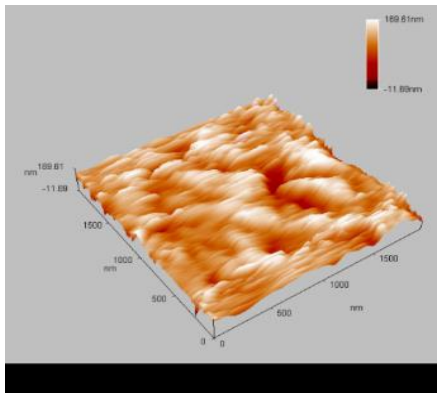

(a)

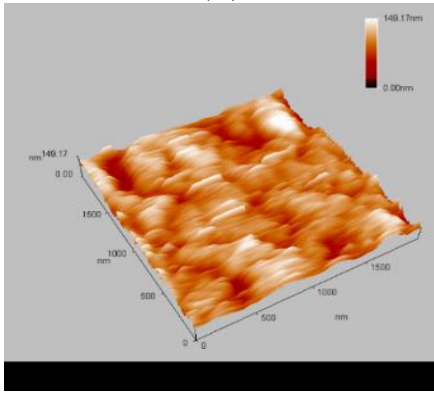

(b)

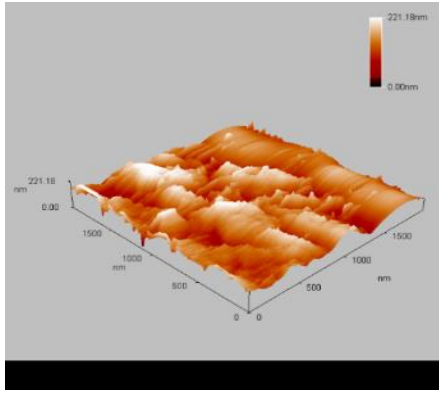

(c)

Fig.(4): AFM images (contact mode) of antimony nanoparticles deposited on copper substrate from 1:5 mole ratio ammonium alum :urea room temperature ionic liquid at $-0.8 \mathrm{~V}$, and $30^{\circ} \mathrm{C}$ after different deposition time (a)1h.,(b)2h.,(c)3h.

Due to the small amount of deposited antimony metal on the surface of copper substrate as stated in Table (1), the X-ray diffraction(XRD) was not helpful to analyze the deposited antimony and only indicated the peaks of copper as shown in Fig.(5). 


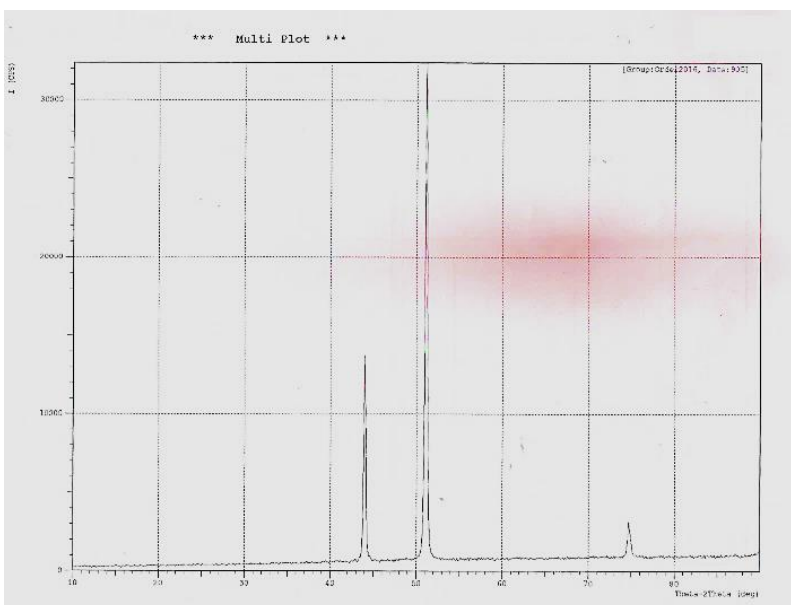

Fig.(5): XRD of antimony electrodeposit on copper substrate from $\mathrm{Sb}(\mathrm{III})$ in aluminum alum: urea room temperature ionic liquid.

Table (1)

Total grain, roughness, average size, average height, \% of Sb coating and particle size of deposited antimony obtained from 1:5 mole ratio ammonium alum: urea room temperature ionic liquid at -0.8 Vand $30^{\circ} \mathrm{C}$ at different deposition time.

\begin{tabular}{|c||c||c||c|c||c||c||c||c|}
\hline No. & $\begin{array}{c}\text { Time } \\
\text { (h.) }\end{array}$ & $\begin{array}{c}\text { Total } \\
\text { grain }\end{array}$ & $\begin{array}{c}\text { Roughness } \\
\text { (Ra) } \\
{[\mathbf{n m}]}\end{array}$ & $\begin{array}{c}\text { Avg. } \\
\left.\text { size[nm }{ }^{2}\right]\end{array}$ & $\begin{array}{c}\text { Avg. } \\
\text { Height } \\
{[\mathbf{n m}]}\end{array}$ & $\begin{array}{c}\text { Sb\% } \\
\text { from } \\
\text { EDAX }\end{array}$ & $\begin{array}{c}\text { Avg. } \\
\text { Diameter } \\
\text { [nm] from (AFM) }\end{array}$ & $\begin{array}{c}\text { Particles } \\
\text { size[nm] } \\
\text { from(SEM) }\end{array}$ \\
\hline \hline 1 & 1 & 593 & 19.0 & 6585.75 & 154.53 & 3.47 & 91.57 & $154-462$ \\
\hline 2 & 2 & 523 & 15.9 & 7434.35 & 120.18 & 3.95 & 97.29 & $227-455$ \\
\hline 3 & 3 & 1058 & 26.9 & 3626.52 & 159.33 & 4.47 & 67.95 & $217-435$ \\
\hline
\end{tabular}

\section{Conclusions}

In this study, we have found that the reduction of antimony from its saturated solution metal chloride in ammonium alum: urea room temperature ionic liquid was possible. The surface morphology of deposited antimony on copper substrate in ammonium alum/urea room temperature ionic liquid was not affected by deposition time at $-0.8 \mathrm{~V}$ and $30^{\circ} \mathrm{C}$. The deposited antimony particles on copper substrate were in nanoparticle scale with a size ranges from $154 \mathrm{~nm}$ to $462 \mathrm{~nm}$.

\section{References}

[1] Wilkes J.S, Levisky J.A., Wilson R.A., and Hussey C.L., "Dialkylimidazolium chloroaluminate melts: a new class of room-temperature ionic liquids for electrochemistry, spectroscopy and synthesis", Inorg. Chem., 21, 1263-1264, 1982.

[2] Earle M.J. and Seddon K.R., "Ionic liquids. Green solvents for the future", Pure Appl. Chem., 72, 1391-1398, 2000.
[3] Hussey C., Mamantov G. and Popov A.I, "Chemistry of nonaqueous Solutions Current Progress", chap.4, 227, 1994.

[4] Carlin R.T. and Wilkes J.S., "Chemistry and speciation in room-temperature chloroaluminate molten salts", chap.5, 277, 345-350, 1994.

[5] Stafford G.R. and Hussey C.L., "Advances in Electrochemical Science and Engineering", 7, 275-279, 2001.

[6] Wilkes J. and Zaworotko M., J., "Air and water stable 1-ethyl-3-methylimidazolium based ionic liquids", Chem. Soc. Chem. Commum., 13, 965-969, 1992.

[7] Abood H.M.A, Abbott A.P, Ballantyne A.D and Ryder K.S, "Do all ionic liquids need organic cations? Characterisation of [AlCl2_nAmide $]^{+} \mathrm{AlCl}_{4}^{-}$and comparison with imidazolium based systems", Chem. Commun., 47, 3523-3525, 2011.

[8] Abood. H. M. A., "New ionic liquid made from hydrated aluminum sulfate with amide", Patent pending, Central Organization for Standardization and Quality, Property division, Application No. 336/2012, 2012. (IRAQ). 
[9] Hassan N.M., Abood H.M.A., Alias M.F., "Study The Electronic Transition Behavior of Divalent Transition Metal Cations Co (II), $\mathrm{Ni}$ (II) and $\mathrm{Cu}(\mathrm{II})$ in Aluminum Nitrate/Urea Room Temperature Ionic Liquid (1:1.2)", IJSR , 4, 1955-1961, 2015.

[10] Al-Qudsi Z.N., Abood H.M.A., "The Electronic Transition Behavior Cr (III), Fe (III), Fe (II) and Ni (II), Transition Metal Cations In Ammonium Alum-Urea Room Temperature Ionic Liquid", J. of AlNahrain University, 16, 46-55, 2013.

[11] Abbott A.P., Ballantyne A., Harris R.C., Jama J.A., Ryder K.S., Forrest G., "A Comparative Study of Nickel Electrodeposition Using Deep Eutectic Solvents and Aqueous Solutions", Electro. Acta, 176, b718-726, 2015.

[12] Jefferson J., National Accelerator Facility - Office of Science Education, its Elemental - The Periodic Table of Elements, accessed December 2014.

[13] Habboush D. and Osteryoung R., Inorg. Chem. 23, 1726, 1984.

[14] Chauhan H., Joshi S., Bakshi A. and CarpenterJ., "Structural investigation on toluene-3,4-dithiolatoantimony(III)

alkyldithiocarbonate complexes: thermal, powder XRD and biological studie" s, New J. Chem., 39, 2279-2288, 2015.

[15] Young P., Brackbill P. and Kandlikar S., "Estimating Roughness Parameters Resulting From Various Machining Techniques for Fluid Flow Applications", J. The American Society of Mechanical Engineers. 827-836, 2007. 